\title{
Iran's Activities on Prevention, Treatment and Harm Reduction of Drug Abuse
}

\author{
Mohammad Bagher Saberi Zafarghandi, ${ }^{1}$ Mohsen Jadidi, ${ }^{2, *}$ and Narjes Khalili ${ }^{3}$ \\ ${ }^{1}$ Department of Addiction, Mental Health Research Center, School of Behavioral Sciences and Mental Health, Tehran Institute of Psychiatry, Iran University of Medical Sciences, \\ Tehran, IR Iran \\ ${ }_{2}^{2}$ Department of Psychology, Bandargaz Branch, Islamic Azad University, Bandargaz, IR Iran \\ ${ }^{3}$ Drug Control Headquarters, Presidency of Islamic Republic of Iran, Tehran, IR Iran \\ ${ }^{*}$ Corresponding author: Mohsen Jadidi, Department of Psychology, Bandargaz Branch, Islamic Azad University, Bandargaz, IR Iran. Tel: +98-9123000074, Fax: +98-2155573754, \\ E-mail: Jadidi@bandargaziau.ac.ir
}

Received 2014 August 17; Revised 2015 March 28; Accepted 2015 April 28.

\begin{abstract}
Context: In the present review study, authors investigated Iran's activities regarding prevention, abuse and harm reduction of drugs nationwide. The issue appears to be important in order to show the trend of activities in the country.

Evidence Acquisition: In this report, authors gathered data from different Farsi/English peer review journals issued both in printed and online versions. These journals have been indexed in PubMed, ISI, ISC, SID, Magiran, UN, etc. These are among the most referred and cited databases.

Results:Summarizing the data led to three distinguished sections:1)drug supply reduction activities;2)drug demand reduction activities; 3) harm reduction activities.

Conclusions: As the results showed, the trend of activities was encouraging and some additional activities could be included to future programs relying on early-onset preventions.

Keywords: Harm Reduction, Drug Abuse, Drug Control
\end{abstract}

\section{Context}

Governments always try to make optimal levels of life standards for their citizens which consist of increasing well-fare and declining harmful conditions. One of the most enduring situations in societies is related to drug abuse. This phenomenon consists of components such as: a) engagement in the behavior to achieve appetitive effects, b) preoccupation with the behavior, c) temporary satiation, d) loss of control, and e) suffering the negative consequences (1). During recent decades, Iran confronted with the increase of drug abuse and related consequences. In this regard, opium and its derivations have been among highly-abused drugs which affect adults.

Although opium use has been reported in Iran since centuries ago, it has currently changed to a problematic issue with widespread psychosocial, familial and economic difficulties. Iran is in the transition line for drugs imported illegally and criminally from Afghanistan and Pakistan, then exported in the same way to Turkey and Europe. There is no clear report on the prevalence of drug abusers in Iran; however, some local reports estimated the presence of 2 - 4 million substance abusers. In addition, the current formal announced number of drug abusers in Iran is about two millions (1 200000 drug dependents and 800000 recreational abusers). In this brief study, some of the main activities were represented which were executed by the Iranian headquarter against drug abuse.

Drug abuse is among the most challenging healthrelated problems which leads to a broad range of physical and psychosocial consequences; the issue burdens several public health problems worldwide $(2,3)$. Opioids are the third most widely used group of drugs after cannabis and amphetamine-type stimulants; opioid dependence leads to different morbidities, increases the risk of physical problems, and might cause injury, obesity, and a decreased quality of life (4-7). Among opioids, opiates are the most problematic and harmful substances, consumed by 12 to 21 million people worldwide. The highest consumption rates of opiates have been reported in countries of southwest Asia $(8,9)$.

Geographically, Iran is located along the opium trade route, with the highest rate of opiate use worldwide. Based on a national survey of drug abuse in Iran, the number of drug dependents that require treatment interventions exceeds 1.2 millions (10). Opiates, mostly opium and heroin hydrochloride (11), are the main drugs of abuse (12). It seems that in recent years, a substantial shift has happened from opium use towards using crystalline

Copyright (C) 2015, Zahedan University of Medical Sciences. This is an open-access article distributed under the terms of the Creative Commons Attribution-NonCommercial 4.0 International License (http://creativecommons.org/licenses/by-nc/4.0/) which permits copy and redistribute the material just in noncommercial usages, provided the original work is properly cited. 
heroin: some new official estimates show that as many as $40 \%$ of opiate users consume opium, whereas the remaining ones use different forms of heroin (8).

In the most recent survey, researchers showed that the order of drugs consumption in Iran is opium (34\%), crack heroin (26.6\%), heroin (19.2\%), opium residue (4.4\%), Norgesic (4.1\%), amphetamines (3.6\%) and cannabis (2\%) (13). Another national survey of drug abuse reported even higher rate of cannabis abuse in Iran (16\%), and demonstrated 15\% abuse rate for amphetamines (14). Demographical issues are also considerable; the mean age at first drug use in Iran is 21 years old (15) and lifetime rates of opiate use among Iranian students are between 1.2 and $8.6 \%$ in different provinces of the country (16).

\section{Evidence Acquisition}

Based on the objective of the present study which was concentrated on drug prevention activities, treatments and harm reduction of the Iranian population, authors in this report recruited well-controlled surveys and studies which ones were accomplished mainly in the country. Most of the data were published in peer review journals from 1995 - 2014 in Farsi and English. The data were searched and gathered from PubMed, information sciences institute (ISI), united nations, scientific information database (SID), Magiran, and also islamic world science citation center (ISC) databases.

\section{Results}

With respect to the issues and problems illustrated earlier, the main activities of the iranian drug control on prevention and treatment of drug abuse was concentrated on countering the drug supply, reducing the demands for drugs, preventing the spread of drug dependency, and implementing programs to reduce related harms. These activities could be classified as follows:

\subsection{Drug Supply Reduction Activities}

Drug abuse is a serious public health problem which could potentially affect almost every person, family and community (17). Accordingly, supply reduction strategies directed toward enforcing the prohibition of illicit drugs and regulating and developing better access to legal drugs. Iran is still one of the main countries in the path of illegal drugs trafficking; opium, cannabis, heroin, and morphine base are originated from Afghanistan and Pakistan and smuggled mainly for markets in Europe, Persian Gulf and Middle Eastern countries. Supply reduction activities in Iran include both protecting the borders and domestic policing activities. No legal or illegal cultivation of narcotic plants have been reported to take place in the Iranian territory in large scales (18).

Islamic Republic of Iran, as well as supply reduction such as cooperating closely with the international narcotics control board, supporting international operations for preventing the extension of chemical precursors used in the illicit manufacture of heroin and amphetaminetype stimulants, has tried to prevent money-laundering and cooperated for developing illicit crop eradication programs by supporting Afghanistan in this respect (13).

\subsection{Drug Demand Reduction Activities}

Islamic Republic of Iran is one of the pioneer countries in developing policies to prevent and treatment drug dependency and HIV/AIDS (19). In revising the antidrug law, notified in 2010, attempts for demand reduction were particularly respected. The principle goals of the preventive programs include improving overall health and quality of life for individuals, families and communities; focusing on both national and local programs could lead to promote well-being, preventing mental disorders and substance abuse (20). The programs intended to reduce the incidence of substance abuse in the society, promote awareness by mass media, especially among youth, and also tried to prevent physical, social and psychological problems that stem from drugs abuse. Training of teachers, parents and employers for primary prevention of drug dependency has been an ongoing program in the country; for example, the Colombo plan drug advisory program (CPDAP) in collaboration with drug control headquarters (DCHQ) in Iran has been performed since 2010 to prevent drug abuse among youth. The first Iranian youth congress in drug abuse prevention, conducted in Tehran, Iran in November 2010 which was followed by a series of youth initiatives was monitored by DCHQ (21).

The drug demand reduction movement was in progress during the last decade (22). Some efforts in national senate of Iran caused remarkable modifications. Amendments in the senate has been a crucial attempt to facilitate the treatment and rehabilitation of drug abusers, for example, the introduction of drug courts, police referral to voluntary treatment programs, and some other alternative approaches to treatment. Drug dependents that refer to treatment centers and receive certified interventions will be protected from criminal prosecution. Treatment outcomes are relatively encouraging. Almost 63\% of Iranian drug abusers had an abstinence period of one week to six months (23).

\subsection{Harm Reduction Activities}

Harm reduction services aimed at alleviate health symptoms as well as social and economic negative consequences of illicit drug and psychotropic abuse. Injecting drug use has been the major mode of HIV transmission in Iran $(24,25)$. Harm reduction is an important component of HIV and drug prevention strategies in Iran. Many national organizations and institutes have important contributions to create comprehensive harm reduction programs, including law enforcement agents, social welfare organizations, trainings, health, and judiciary sectors. Prisons can also play a significant role in restricting 
the spread of HIV in closed settings and in ensuring support for those who are released back into the community. Religious-related activities and programs as a crucial cultural component have been considered to reduce the risk factors. Harm reduction programs are now implemented by both governmental and nongovernmental services. Three-angular clinics that integrate services for treatment and prevention of sexually transmitted infections, injecting drug use (IDU), and HIV/AIDS, are among the best plans executed both in prisons and nongovernmental organizations (NGO). It provides needle exchange, methadone maintenance treatment (MMT), general medical care, and referral for voluntary counseling and testing. The program is performed in centers for street-based intravenous (IV) drug abusers as a part of continuum of care, and services include providing food, clothes and other basic needs (13).

In 2005, harm reduction was assigned as an official policy in Iran. Consistent with this policy, prisoners in Iran now access legally to methadone under the control of licensed physicians and there have been pilot strategies in prisons to control needle exchange; it has been reported that addicted prisoners could benefit methadone to decrease the spread of infections, injecting drugs, and illegal use of other substances (26-28). The introduction of MMTs has been increased in prisons and secure environments (29). Data of a survey in 2007 on injecting drugs revealed that $95 \%$ of drug injectors used safe equipment since their last injection and syringe sharing among IV drug users was reduced. (30). The rate of new HIV infections in Iran rose until 2005 and then decreased gradually; in $2008,18 \%$ of injecting drug users were HIVpositive; experts believed that this was related to harm reduction policies, otherwise it could reach up to $40 \%$. Regarding the large number of HIV-positive cases among IV drug users and considering that injection drug use is the main spreading factor for HIV in Iran, some local authors have proposed the use of MMT to control epidemics of HIV by reducing drug injection and related risky behaviors (31). At the end of 2010, 191 harm reduction centers (transitional centers) and 321 mobile teams were actively working in the country. Transitional centers and mobile teams have covered 106894 and 75647 people, respectively. Likewise, 109 centers provide MMT with low threshold. Transitional Centers in 2011 distributed 2331215 syringes and needles among clients of transitional centers. In this program, 749850 contaminated syringes and needles were collected and eliminated by the centers and also active mobile teams. After releasing, 1260 prisoners were covered freely by governmental treatment centers to keep on their maintenance treatment. Along with medicinal treatment, 253132 training sessions were held in these centers to train for preventing AIDS and other blood-transmitted diseases (32). As a whole, reports on this domain indicated that needle exchange programs were associated with positive outcomes (29,33-36).

Women at risk play a critical role on spreading HIV epidemic to the general population and nearly $40 \%$ of Iranian women who are seeking drug treatment are sexually active (37); hence, developing the centers would provide more powerful access to this population, and for this means, in 2007, five pilot centers were established at risky areas to deliver comprehensive services to women who themselves or their spouses were engaged in drug use, risky sexual behaviors or had the history of imprisonment. The management of sexually-transmitted infections, psychological counseling, and harm reduction provided by female staff in such centers are some of these services (38). Among low and middle-income countries, high coverage has also been reported in Iran (39). In the Table 1, some of the studies presented in the context are shown based on their objectives.

Table 1. Studies on Drug Prevention and Treatment ${ }^{\mathrm{a}}$

\begin{tabular}{|c|c|c|c|c|}
\hline Author & Date & Location & Sample & Finding(s) \\
\hline De La Haye (17) & 2004 & Jamaica & - & community prevention programs are effective \\
\hline Mojtabazadeh et al. (20) & 2008 & Iran & 478 & suggestion prevention programs \\
\hline The Colombo plan (21) & 2011 & Iran & - & training youth leaders about prevention drugs \\
\hline Vazirian (22) & 2003 & Iran & - & preventive programs should be multifaceted \\
\hline Sharifi et al. (23) & 2012 & Iran & 1372 & many addicted patients preferred self-therapies \\
\hline Haghdoost et al. (25) & 2011 & Iran & - & HIV epidemic pattern will change from unsafe injection to unprotected sex \\
\hline Shoenbaum et al. (26) & 1989 & USA & 452 & social settings and behavior-related factors of drug use predispose people for HIV \\
\hline Rafiey et al. (30) & 2009 & Iran & 2091 & $\begin{array}{c}\text { needle and syringe sharing increased in female IDUs, jobless ones, and people with } \\
\text { illegal income }\end{array}$ \\
\hline Noori et al. (31) & 2012 & Iran & 150 & MMT could play a major role in reducing HIV through decreasing heroin use \\
\hline Kaiser Family Foundation (32) & 2010 & Iran & - & harm reduction had become an official policy in Iran \\
\hline Dolan et al. (37) & 2011 & Iran & 78 & services needed for women to facilitate their entry into drug treatment \\
\hline Fahimfar et al. (38) & 2013 & Iran & 442 & $\begin{array}{l}\text { increasing female centers for the treatment of drug abuse could be effective in } \\
\text { decreasing HIV }\end{array}$ \\
\hline
\end{tabular}

a Abbreviations: MMT, methadone maintenance treatment; IDU, injecting drug use. 


\section{Conclusions}

As findings showed, programs and activities for reducing drug abuse in Iran have been encouraging and there has been a progressive trend to achieve determined objectives in the upcoming years. Literature in this domain pointed that preventive programs were generally accompanied with positive outcomes, particularly once they began early before the prevalence of problem in different populations (40-43). It seems essential to perform intermittent evaluations of ongoing programs and prepare recommendations and suggestions based on findings of the activities to reach better performance and more possible results.

\section{Acknowledgments}

The authors thank the institute of psychiatry, school of behavioral sciences and mental health, mental health research center, Iran university of medical sciences, which provided us the opportunity to prepare the manuscript. Also the authors thank the colleagues in international journal of high risk behaviors and addiction who provided a valuable condition for authors to share their data.

\section{Footnote}

Authors' Contribution:Mohammad Bagher Saberi Zafarghandi prepared the article and edited it. Mohsen Jadidi prepared the English version of the article. Narjes Khalili reviewed the whole paper and edited its contents and structure.

\section{References}

1. Sussman S, Sussman AN. Considering the definition of addiction. Int J Environ Res Public Health. 2011;8(10):4025-38. doi: 10.3390/ ijerph8104025. [PubMed:22073026]

2. Chen CY, Lin KM. Health consequences of illegal drug use. Curr Opin Psychiatry. 2009;22(3):287-92. [PubMed: 19378381]

3. Alam Mehrjerdi Z. Crystal in Iran: methamphetamine or heroin kerack. Daru. 2013;21(1):22. doi: 10.1186/2008-2231-21-22. [PubMed: 23497450]

4. Kato I, Zeleniuch-Jacquotte A, Toniolo PG, Akhmedkhanov A, Koenig K, Shore RE. Psychotropic medication use and risk of hormone-related cancers: the New York University Women's Health Study. J Public Health Med. 2000;22(2):155-60. [PubMed:10912553]

5. Challier B, Chau N, Predine R, Choquet M, Legras B. Associations of family environment and individual factors with tobacco, alcohol, and illicit drug use in adolescents. Eur J Epidemiol. 2000;16(1):33-42. [PubMed:10780340]

6. Torrens M, Domingo-Salvany A, Alonso J, Castillo C, San L. Methadone and quality of life. Lancet. 1999;353(9158):1101. doi: 10.1016| s0140-6736(05)76462-x. [PubMed:10199379]

7. Virk S, Schwartz TL, Jindal S, Nihalani N, Jones N. Psychiatric medication induced obesity: an aetiologic review. Obes Rev. 2004;5(3):167-70. doi: 10.1111/j.1467-789X.2004.00141.x. [PubMed: 15245385]

8. United Nations Office on Drugs and Crime. World Drug Report, Sales No. E.11.XI.10. Vienna; United Nations Publication. 2011.

9. Kulsudjarit K. Drug problem in southeast and southwest Asia Ann N Y Acad Sci. 2004;1025:446-57. doi: 10.1196/annals.1316.055. [PubMed: 15542748]

10. Iranian Drug Control Headquarter IP . National Rapid Situation Analysis of Drug Abuse Status in Iran. Iran: IDCH; 2007. Available from: http://dchq.ir/en/index.php?option=com_content\&view= article\&id=1171\&Itemid=1002.

11. Zerell U, Ahrens B, Gerz P. Documentation of a heroin manufacturing process in Afghanistan. Bull Narc. 2005;57(1-2):11-31. [PubMed: 21338014]

12. Meysamie A, Sedaghat M, Mahmoodi M, Ghodsi SM, Eftekhar B. Opium use in a rural area of the Islamic Republic of Iran. East Mediterr Health J. 2009;15(2):425-31. [PubMed:19554990]

13. United Nation Office on Crime and Drugs. UNODC global vision on prevention, treatment and care of drug abuse and HIV/AIDS. Islamic Republic of Iran: United Nation Office on Crime and Drugs; 2012. Available from: https://www.unodc.org/islamicrepublicofiran/ en/unodc-global-vision.html.

14. Shekarchizadeh H, Ekhtiari H, Khami MR, Virtanen JI. Patterns of pre-treatment drug abuse, drug treatment history and characteristics of addicts in methadone maintenance treatment in Iran. Harm Reduct J. 2012;9:18. doi:10.1186/1477-7517-9-18. [PubMed: 22676557]

15. Daneshmandan N, Narenjiha H, Tehrani K, Assari S, KhoddamiVishteh HR. Initiation to the first drug use among substancedependent persons in Iran. Subst Use Misuse. 2011;46(9):1124-41. doi:10.3109/10826084.2010.490971. [PubMed:21345165]

16. Momtazi S, Rawson R. Substance abuse among Iranian high school students. Curr Opin Psychiatry. 2010;23(3):221-6. doi: 10.1097/YCO.ob013e328338630d. [PubMed: 20308905]

17. De La Haye W. Community-based prevention of substance abuse. West Indian Med J. 2004;53(6):420-3. [PubMed:15816272]

18. United Nations Office on Drugs and Crime. 2012 World Drug Report, Sales No. E.12.XI.1. Vienna;. 2012.

19. United Nations Office on Drugs and Crime. 2013 World Drug Report, Sales No. E.13.XI.6. Vienna;. 2013.

20. Mojtahedzadeh V, Razani N, Malekinejad M, Vazirian M, Shoaee $S$, Saberi Zafarghandi MB, et al. Injection drug use in Rural Iran: integrating HIV prevention into iran's rural primary health care system. AIDS Behav. 2008;12(4 Suppl):S7-12. doi: 10.1007/s10461008-9408-y. [PubMed: 18521737]

21. The Colombo Plan. dvanced Training for Youth leaders and Workshop on the Development of Manual for Drug Abuse Prevention among Iranian Youth 1st Batch. Sri Lanka: ICCE; Available from: http://www.colombo-plan.org/index.php/.

22. Vazirian M. Review of drug demand reduction programs in Iran: Advices for development and strategic planning. Soc Welfare. 2003;3:145-201.

23. Sharifi H, Kharaghani R, Sigari S, Emami H, Sadr M, Masjedi M. Common methods to treat addiction in treatment- rehabilitation centers in tehran. Iran J Public Health. 2012;41(4):63-8. [PubMed: 23113166]

24. National AIDS Committee Secretariat Ministry of Health and Medical Education Islamic Republic of Iran. AIDS Progress Report On Monitoring of the United Nations General Assembly Special Session on HIV and AIDS. 2012. Available from: http://www.unaids. org/en/dataanalysis/knowyourresponse/countryprogressreport s/2012countries.

25. Haghdoost AA, Mostafavi E, Mirzazadeh A, Navadeh S, Feizzadeh A, Fahimfar N, et al. Modelling of HIV/AIDS in Iran up to 2014. $J$ AIDS HIV Res. 2011;3(12):231-9.

26. Schoenbaum EE, Hartel D, Selwyn PA, Klein RS, Davenny K, Rogers $\mathrm{M}$, et al. Risk factors for human immunodeficiency virus infection in intravenous drug users. N Engl J Med. 1989;321(13):874-9. doi:10.1056/NEJM198909283211306. [PubMed:2770823]

27. Farrell M, Ward J, Mattick R, Hall W, Stimson GV, des Jarlais D, et al. Methadone maintenance treatment in opiate dependence: a review. BMJ.1994;309(6960):997-1001. [PubMed: 7950725]

28. Hutchinson SJ, Taylor A, Gruer L, Barr C, Mills C, Elliott L, et al. One-year follow-up of opiate injectors treated with oral methadone in a GP-centred programme. Addiction. 2000;95(7):1055-68. [PubMed: 10962770]

29. Wright NM, French C, Allgar V. The safe implementation of a prison-based methadone maintenance programme: 7 year timeseries analysis of primary care prescribing data. BMC Fam Pract. 2014;15:64. doi: 10.1186/1471-2296-15-64. [PubMed: 24712316]

30. Rafiey H, Narenjiha H, Shirinbayan P, Noori R, Javadipour M, Ro- 
shanpajouh $\mathrm{M}$, et al. Needle and syringe sharing among Iranian drug injectors. Harm Reduct J. 2009;6:21. doi: 10.1186/1477-7517-621. [PubMed: 19643014]

31. Noori R, Narenjiha H,Aghabakhshi H, Habibi G, Khoshkrood Mansoori B. Methadone maintenance therapy outcomes in Iran. Subst Use Misuse. 2012;47(7):767-73. doi: 10.3109/10826084.2010.517726. [PubMed: 22416897]

32. Kaiser HJ. Praise for Iran's Harm Reduction Program. Henry J. Kaiser Family Foundation; 2010. Available from: http://www.thebody. com/index/whatis/demo_mideast.html\#iran.

33. Des Jarlais DC, Hagan H, Friedman SR, Friedmann P, Goldberg D, Frischer M, et al. Maintaining low HIV seroprevalence in populations of injecting drug users. Jama. 1995;274(15):1226-31. [PubMed: 7563513]

34. Hagan H, Jarlais DC, Friedman SR, Purchase D, Alter MJ. Reduced risk of hepatitis $B$ and hepatitis $C$ among injection drug users in the Tacoma syringe exchange program. Am J Public Health. 1995;85(11):1531-7. [PubMed:7485666]

35. Vlahov D, Junge B, Brookmeyer R, Cohn S, Riley E, Armenian H, et al. Reductions in high-risk drug use behaviors among participants in the Baltimore needle exchange program. J Acquir Immune Defic Syndr Hum Retrovirol. 1997;16(5):400-6. [PubMed: 9420320]

36. Drucker E, Lurie P, Wodak A, Alcabes P. Measuring harm reduction: the effects of needle and syringe exchange programs and methadone maintenance on the ecology of HIV. AIDS. 1998;12
Suppl A:S217-30. [PubMed: 9633006]

37. Dolan K, Salimi S, Nassirimanesh B, Mohsenifar S, Allsop D, Mokri A. Characteristics of Iranian women seeking drug treatment. J Womens Health (Larchmt). 2011;20(11):1687-91. doi:10.1089/ jwh.2010.2694. [PubMed: 21905877]

38. Fahimfar N, Sedaghat A, Hatami H, Kamali K, Gooya M. Counseling and Harm Reduction Centers for Vulnerable Women to HIV|AIDS in Iran. Iran J Public Health. 2013;42(Supple1):98-104. [PubMed: 23865025]

39. Stoicescu C. The Global State of Harm Reduction 2012: Towards an Integrated Response. London: 2012.

40. Hahn EJ, Simpson MR, Kidd P. Cues to parent involvement in drug prevention and school activities. J Sch Health. 1996;66(5):165-70. [PubMed: 8735580]

41. Sussman S. Development of a school-based drug abuse prevention curriculum for high-risk youths. J Psychoactive Drugs. 1996;28(2):169-82. doi: $\quad 10.1080 / 02791072.1996 .10524389$. [PubMed: 8811585]

42. Ishaak F, de Vries NK, van der Wolf K. Test implementation of a school-oriented drug prevention program "Study without Drugs": pre- and post-testing for effectiveness. BMC Public Health. 2014;14:590. doi:10.1186/1471-2458-14-590. [PubMed: 24920468]

43. Mihalic SF, Fagan AA, Argamaso S. Implementing the LifeSkills Training drug prevention program: factors related to implementation fidelity. Implement Sci. 2008;3:5. doi: 10.1186/1748-5908-3-5. [PubMed: 18205919] 